\title{
CONFLITOS SOCIOAMBIENTAIS NA APA EM ESTÂNCIA/SE
}

Fagner Santos de Oliveira ${ }^{1}$ Márcia Eliane Silva Carvalho ${ }^{2}$

Resumo: As Unidades de Conservação têm sofrido com as ações antrópicas, as quais resultam de diversos interesses, principalmente econômicos. A Área de Proteção Ambiental (APA) Litoral Sul de Sergipe, engloba todo o litoral do município de Estância/SE, e ilustra essa realidade. O objetivo deste artigo consiste em classificar, mapear e analisar os Conflitos Socioambientais na APA do litoral de Estância. Para tanto, utilizou-se a metodologia de diagnóstico dos Conflitos Socioambientais, proposta pela categorização literário-analítica de Paul Little (2001), numa abordagem quali-quantitativa. Esta pesquisa serve como subsídio para a leitura dos Conflitos Socioambientais existentes na APA, tendo em vista a busca por ações eficazes em prol do uso sustentável de seus recursos naturais.

Palavras-chave: Unidade de Conservação. Território. Recursos naturais. Comunidades tradicionais. Sustentabilidade.

\section{SOCIO-ENVIRONMENTAL CONFLICTS IN APA ESTÂNCIA/SE}

Abstract: Conservation Units have suffered from anthropic actions, which result from diverse interests, mainly economic. The Environmental Protection Area (APA) South Coast of Sergipe, encompasses the entire coast of the municipality of Estância/SE, and illustrates this reality. The objective of this article is to classify, map and analyze the Social and Environmental Conflicts in the APA of the Estância coast. For that, we used the Socio-Environmental Conflict diagnostic methodology, proposed by Paul Little's (2001) literary-analytical categorization, in a qualitative and quantitative approach. This research serves as a subsidy for the reading of the Social and Environmental Conflicts existing in the APA, in view of the search for effective actions in favor of the sustainable use of its natural resources.

Keywords: Conservation Unit. Territory. Natural resources. Traditional communities. Sustainability.

\section{CONFLICTOS SOCIOAMBIENTALES EN APA EN ESTÂNCIA/SE}

Resumen: Las Unidades de Conservación han sufrido acciones antrópicas, que resultan de diversos intereses, principalmente económicos. La Costa Sur de Sergipe del Área de Protección Ambiental (APA), abarca toda la costa del municipio de Estância/SE, e ilustra esta realidad. El objetivo de este artículo es clasificar, mapear y analizar los conflictos sociales y ambientales en la APA de la costa de Estância. Para eso, utilizamos la metodología de diagnóstico de Conflictos Socioambientales, propuesta por la categorización literario-analítica de Paul Little (2001), en un enfoque cualitativo y cuantitativo. Esta investigación sirve como un subsidio para la lectura de los conflictos sociales y ambientales existentes en la APA, en vista de la búsqueda de acciones efectivas a favor del uso sostenible de sus recursos naturales.

\footnotetext{
1 Universidade Federal de Sergipe, Departamento de Geografia, São Cristóvão, Brasil, fagnerdeoliveira@hotmail.com, https://orcid.org/0000-0002-4634-295X

2 Universidade Federal de Sergipe, Departamento de Geografia, São Cristóvão, Brasil, marciacarvalho_ufs@yahoo.com.br, https://orcid.org/0000-0003-2209-6341
} 
Palabras clave: Unidad de Conservación. Territorio. Recursos naturales. Comunidades tradicionales. Sostenibilidad.

\section{Introdução}

Etimologicamente o termo conflito corresponde a embate. Na prática ele evidencia uma falta de entendimento entre as partes envolvidas. O Conflito Socioambiental surge quando o cerne do conflito gravita em torno de disputas entre diferentes atores ou grupos sociais nas ecológicas. Essa disputa acontece tendo em vista a utilização de um mesmo bem material, isto é, do recurso ambiental pleiteado.

Os recursos naturais são cada vez mais objeto das disputas travadas em sociedade. As Unidades de Conservação (UCs), sobremaneira em ambientes litorâneos, têm sofrido cada vez mais com as ações antrópicas. Elas resultam de diversos interesses, principalmente econômicos. Atrelado a isto temos o desconhecimento de sua finalidade jurídica pelos atores envolvidos, associada à negligência fiscalizatória do poder público.

Atualmente reconhece-se a real necessidade de se promover um desenvolvimento que seja capaz de assegurar o acesso aos recursos naturais para as gerações futuras. Em consonância com todo o ordenamento ambiental vigente, que almeja o desenvolvimento sustentável, foram instituídas as Unidades de Conservação, mediante o ordenamento jurídico da Lei n 9.985/2000, através da qual criou-se o Sistema Nacional de Unidades de Conservação.

A Área de Proteção Ambiental (APA) Litoral Sul de Sergipe corresponde a uma dessas UCs caracterizada como de Uso Sustentável, e engloba todo o litoral do município de Estância/SE, na qual encontram-se 16 (dezesseis) comunidades locais e tradicionais. O objetivo deste artigo consiste em classificar, mapear e analisar os Conflitos Socioambientais na APA do litoral de Estância. Para isto, utilizou-se a metodologia de diagnóstico dos Conflitos Socioambientais, proposta pela categorização literário-analítica de Paul Little (2001), numa abordagem qualiquantitativa.

$\mathrm{Na}$ fundamentação teórica realizou-se consistente pesquisa bibliográfica. A coleta dos dados se deu através de visitas in loco, na qual obteve-se fotografias georeferenciadas (pelo Open Camera) e imagens de satélite (pelo UTM Geo Map). Realizou-se entrevistas e questionários semiestruturados aplicados aos principais atores envolvidos. Por fim, procedeu-se a análise dos dados, e a elaboração de um mapa de Conflitos Socioambientais, por meio do QGis 2.18. 


\section{Classificação, mapeamento e análise dos Conflitos Socioambientais em geral}

O termo "conflito" tem sua origem etimológica no latim conflictu e corresponde a choque, embate, peleja. Ele corresponde a uma profunda falta de entendimento entre duas ou mais partes (NASCIMENTO, 2010). A noção de Conflito Socioambiental difere segundo a visão de mundo do sujeito. De modo genérico o conflito decorre da disputa pela apropriação e pelo uso dos recursos naturais.

A imposição dos interesses dominantes é determinante no desfecho desse embate. Cada conflito possui uma forma peculiar de se manifestar, tem uma lógica própria, uma evolução particular (BURSZTYN, 2001). O reconhecimento desses conflitos nem sempre é tarefa fácil, a exemplo dos Conflitos Socioambientais encontrados na APA de Estância/SE.

A APA Litoral Sul de Sergipe, que compreende a faixa costeira dos municípios de Itaporanga d'Ajuda, Estância, Santa Luzia do Itanhi e Indiaroba, conforme ilustrado na Figura 1, foi instituída pelo Decreto $n^{\circ}$ 13.468, de 22 de janeiro de 1993. Ela abrange uma área de 54 mil hectares, situada entre a foz do Rio Vaza Barris e a desembocadura do Rio Real, com cerca de $55,5 \mathrm{~km}$ de costa e largura variável de 10 a 12 km, do litoral para o interior.

Figura 1 - Localização da APA Litoral Sul no recorte de Estância/SE
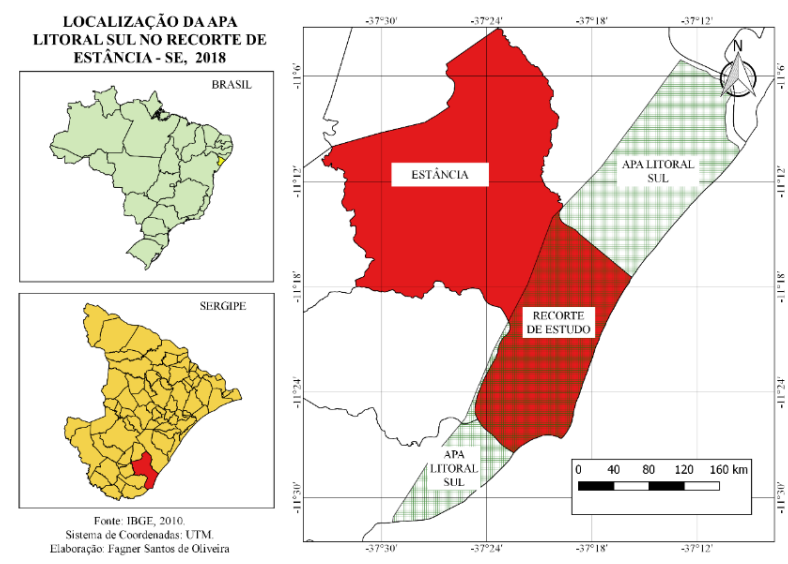

Fonte: O autor (2020).

Desde seu processo histórico de ocupação, em 1575, até os dias hodiernos, essa área passa por contínuas transformações decorrentes das ações antrópicas, as quais foram acentuadas pelas políticas públicas implementadas, sobremodo, a partir da década de 1970. O litoral estanciano "apresenta ambientes naturais marcantes que vem sendo degradados por conta de atividades humanas, diferenciadas pelos vários tipos de uso" (OLIVEIRA, 2014, p. 324). 
Portanto, as comunidades locais e tradicionais contemplaram um frenético processo desenvolvimentista e testemunharam 0 surgimento de Conflitos Socioambientais de diferentes naturezas. Sua delimitação e mapeamento são imprescindíveis para a compreensão de como o uso e ocupação da APA de Estância avançaram até os dias atuais, fato que ajudaria a comunidade local no seu entendimento e na realização de políticas públicas voltadas para o uso sustentável de seus recursos naturais.

As comunidades que integram a Área de Proteção Ambiental do litoral de Estância podem ser destacadas em 03 (três) agrupamentos distintos: as concentradas na praia (Abaís, Boa Viagem, Dunas e Saco); as fundadas às margens e adjacências da rodovia SE-100 (Manuel Dias, Massadiço, Cachoeirinha, Coqueiro de Dentro, Coqueiro de Fora, Ribuleira Grande, Ribuleirinha e Porto do Mato); e as situadas às margens do Rio Pagão (Farnaval, Ribeiro, Tibúcio e Ouricuri); perfazendo o total de 16 (dezesseis) povoações.

As comunidades praianas concentram suas atividades econômicas principalmente no desenvolvimento do turismo e na prática da pesca artesanal. Os demais povoados, excetuando-se o Porto do Mato onde o turismo também é desenvolvido, concentram suas atividades econômicas principalmente no extrativismo dos recursos naturais encontrados na APA. Isso deve-se às raízes históricas de sua povoação, bem como decorre das políticas públicas implementadas recentemente na área.

A classificação dos Conflitos Socioambientais proposta por Little (2001) serve como ferramenta prática e pedagógica para o reconhecimento de conflitos na Área de Proteção Ambiental do litoral de Estância/SE ou em qualquer outro recorte espacial. As informações obtidas foram sistematizadas e tipificadas segundo três grupos propostos pelo autor: 1) os conflitos socioambientais em torno do controle sobre os recursos naturais; 2) os conflitos em torno dos impactos ambientais e sociais gerados pela ação humana e natural; e 3) os conflitos em torno do uso dos conhecimentos ambientais. Esses resultados possibilitaram a elaboração de um mapa com todos os Conflitos Socioambientais encontrados na APA do litoral de Estância, conforme disposto na Figura 2. 
Figura 2 - Conflitos Socioambientais na APA do litoral de Estância/SE

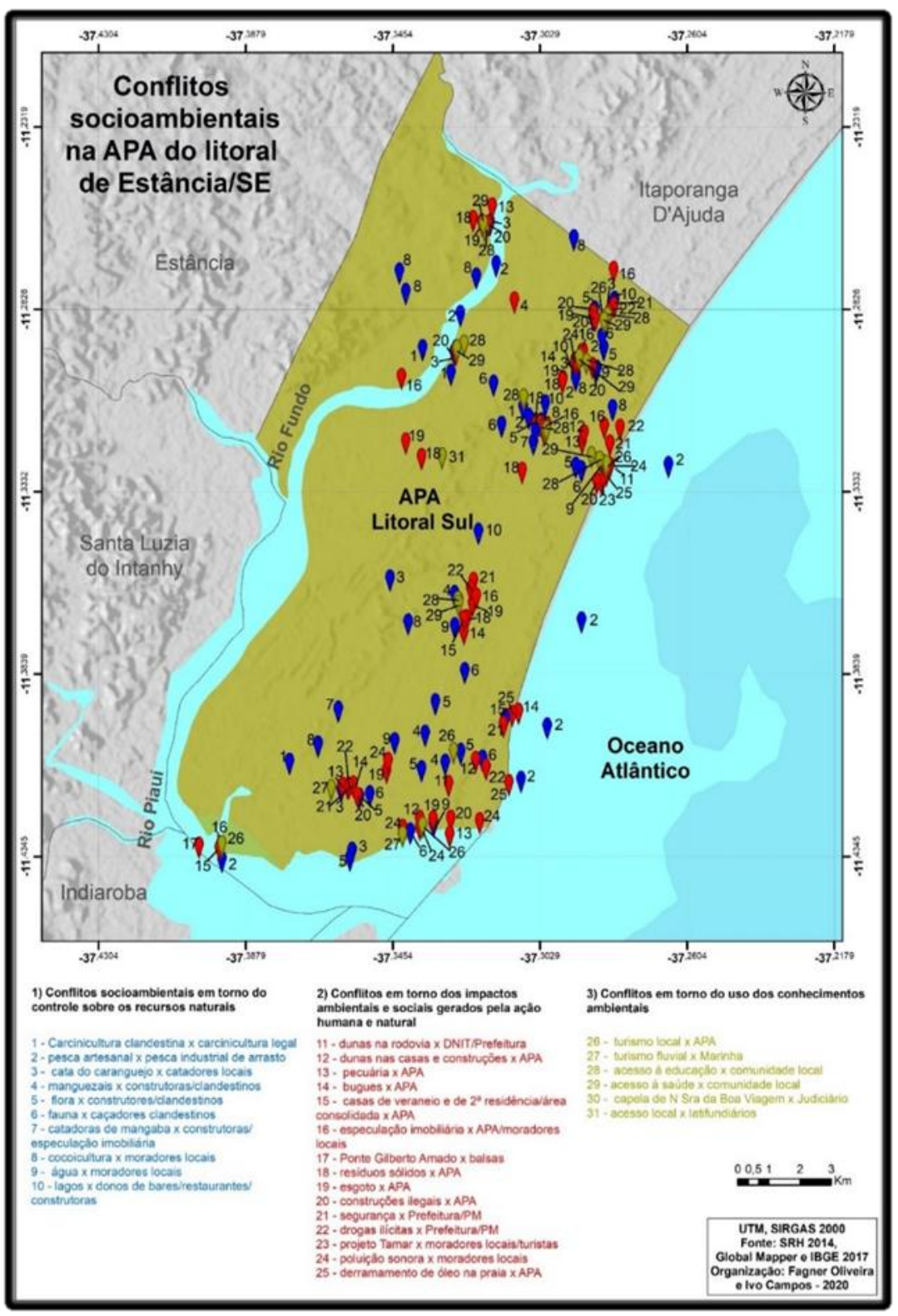

Fonte: O autor (2020).

O diagnóstico quantitativo do referido mapa perfaz 31 (trinta e um) tipos distintos de Conflitos Socioambientais. No grupo dos conflitos em torno do controle dos recursos naturais encontram-se 10 (dez) espécies dos mesmos; no grupo dos conflitos em torno dos impactos gerados pela ação humana e natural encontram-se 15 (quinze) tipos deles; e no grupo dos conflitos em torno do uso dos conhecimentos ambientais encontram-se 6 (seis) tipos deles. O gráfico seguinte, na Figura 3, foi elaborado a partir dos resultados colhidos in loco e destaca o percentual dos conflitos socioambientais encontrados na APA do litoral estanciano segundo os três grupos propostos por Little (2001). 
Figura 3 - Percentual de Conflitos Socioambientais na APA estanciana segundo Little (2001).

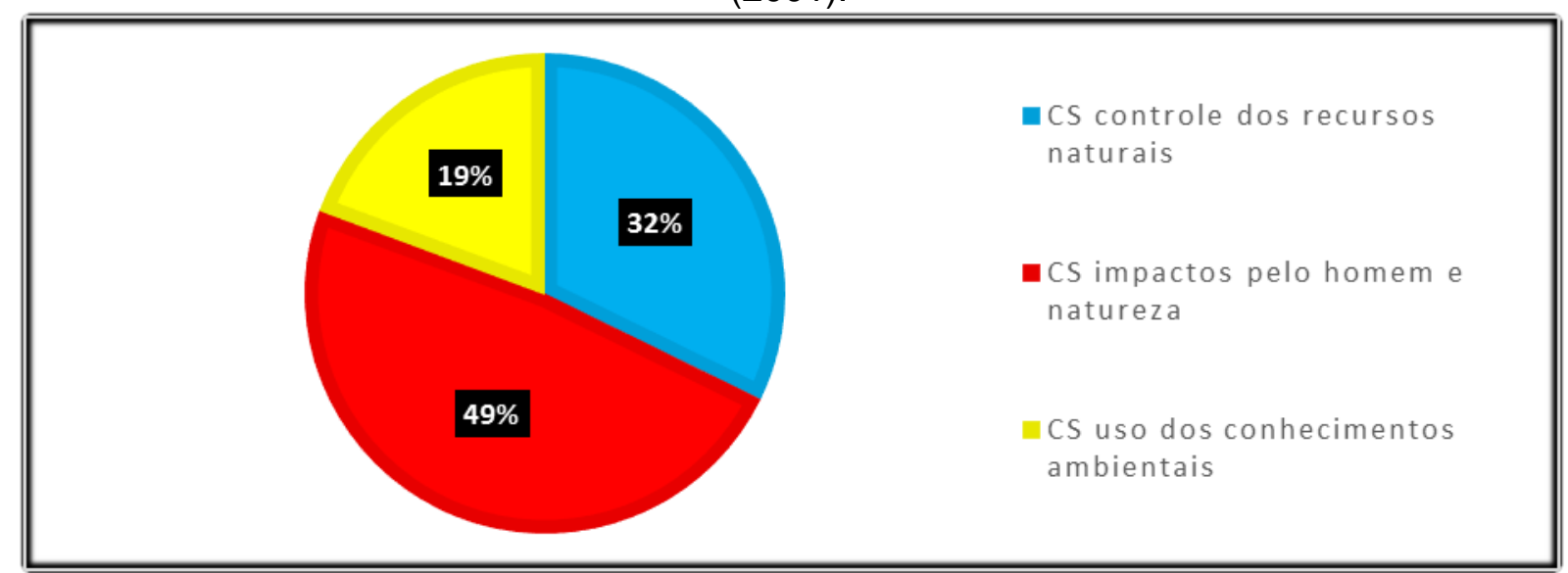

Organização: O autor (2019).

O grupo dos Conflitos Socioambientais em torno dos impactos gerados pela ação humana e natural possui o maior percentual de conflitos, $49 \%$, ou seja, quase a metade dos mesmos se enquadram nessa tipificação. Isso evidencia a relação degradante que as ações antrópicas têm ocasionado na APA do litoral estanciano.

Ao longo das últimas décadas isso tem acontecido num ritmo cada vez mais acelerado. A ausência de políticas públicas, que possam favorecer uma relação ecologicamente sustentável do ser humano com o meio natural, também auxilia no entendimento dessas circunstâncias. De modo similar entende-se as frações encontradas no grupo dos Conflitos Socioambientais em torno do controle dos recursos naturais, as quais perfazem 32\% deles. A apropriação dos recursos naturais existentes na APA tem ocasionado inúmeros conflitos, ameaçando a sua sustentabilidade.

Por fim, o grupo dos Conflitos Socioambientais em torno do uso dos conhecimentos ambientais corresponde a $19 \%$ dos conflitos nessa área. Este resultado evidencia a necessidade que se impõe em investir em políticas públicas que possibilitem a formação das comunidades locais e tradicionais. Além disso, fazse necessário investir em políticas sociais que promovam a conscientização ambiental dos turistas e proprietários de casas de segunda residência, tendo em vista o conhecimento e esclarecimento do que seja uma APA, e da importância de sua preservação.

Isto faz-se imprescindível, sobremodo, em tempos de forte visitação turística, como no verão, nas férias e em tempos festivos da comunidade, tais como carnaval, São João e virada de ano. Afinal, nestes períodos o fluxo de turistas aumenta 
consideravelmente na APA, tornando-a mais vulnerável a degradações, poluições e conflitos das mais diferentes naturezas.

\section{Conflitos Socioambientais em torno do controle sobre os recursos naturais}

Nessa tipologia de Little (2001), conforme apresentado no Quadro 1, identificam-se os Conflitos Socioambientais em torno do controle sobre os recursos naturais, os quais sintetizam 32\% dos Conflitos Socioambientais encontrados no litoral de Estância. Eles estão espalhados por diversas comunidades ao longo da APA e ilustram interesses de preservação, econômicos, extrativistas, particulares, etc. Eles caracterizam-se pela apropriação dos recursos naturais.

Quadro 1 - Planilha dos CS em torno do controle sobre os recursos naturais na APA do litoral de Estância.

\begin{tabular}{|c|c|c|c|}
\hline $\begin{array}{l}\text { TIPO DE } \\
\text { CONFLITO }\end{array}$ & $\begin{array}{c}\text { ATORES } \\
\text { ENVOLVIDOS }\end{array}$ & $\begin{array}{c}\text { RECURSOS } \\
\text { EM } \\
\text { DISPUTA }\end{array}$ & LOCAIS DE OCORRÊNCIA \\
\hline Carcinicultura & $\begin{array}{c}\text { Carcinicultores } \\
\text { legais x } \\
\text { clandestinos }\end{array}$ & Camarão & $\begin{array}{l}\text { Cachoeirinha, Coqueiro de Dentro, Porto do Mato, } \\
\text { Manuel Dias, Associação de Pescadores e } \\
\text { Marisqueiras do Porto do Mato, Movimento das } \\
\text { Marisqueiras de Sergipe }\end{array}$ \\
\hline Pesca & $\begin{array}{l}\text { Pesca } \\
\text { artesanal } x \\
\text { Pesca } \\
\text { industrial de } \\
\text { arrasto }\end{array}$ & Peixes & $\begin{array}{l}\text { Manuel Dias, Cachoeirinha, Praia do Abaís, } \\
\text { Coqueiro de Dentro, Ribuleira, Praia das Dunas, } \\
\text { Porto do Mato, Associação de Pescadores e } \\
\text { Marisqueiras do Porto do Mato, Associação das } \\
\text { Catadoras de Mangaba, Movimento das } \\
\text { Marisqueiras de Sergipe }\end{array}$ \\
\hline Caranguejo & $\begin{array}{l}\text { IBAMA X } \\
\text { catadores } \\
\text { locais }\end{array}$ & Caranguejo & $\begin{array}{l}\text { Manuel Dias, Cachoeirinha, Coqueiro de Dentro, } \\
\text { Ribuleira, Praia das Dunas, Porto do Mato, } \\
\text { Associação das Catadoras de Mangaba, } \\
\text { Movimento das Marisqueiras de Sergipe }\end{array}$ \\
\hline Manguezais & $\begin{array}{c}\text { IBAMA x } \\
\text { construtoras e } \\
\text { clandestinos }\end{array}$ & $\begin{array}{l}\text { Áreas de } \\
\text { mangue }\end{array}$ & $\begin{array}{l}\text { Manuel Dias, Ribuleira, Praia das Dunas, Porto do } \\
\text { Mato, Associação de Pescadores e Marisqueiras do } \\
\text { Porto do Mato, Associação das Catadoras de } \\
\text { Mangaba, Movimento das Marisqueiras de Sergipe }\end{array}$ \\
\hline Flora & $\begin{array}{c}\text { IBAMA x } \\
\text { construtoras e } \\
\text { clandestinos }\end{array}$ & $\begin{array}{c}\text { Restingas e } \\
\text { vegetação } \\
\text { nativa }\end{array}$ & $\begin{array}{l}\text { Manuel Dias, Cachoeirinha, Praia do Abaís, } \\
\text { Coqueiro de Dentro, Ribuleira, Praia das Dunas, } \\
\text { Porto do Mato, Associação de Pescadores e } \\
\text { Marisqueiras do Porto do Mato, Associação das } \\
\text { Catadoras de Mangaba, Movimento das } \\
\text { Marisqueiras de Sergipe }\end{array}$ \\
\hline
\end{tabular}




\begin{tabular}{|c|c|c|c|}
\hline Fauna & $\begin{array}{l}\text { IBAMA x } \\
\text { caçadores } \\
\text { clandestinos }\end{array}$ & $\begin{array}{l}\text { Animais } \\
\text { nativos }\end{array}$ & $\begin{array}{l}\text { Manuel Dias, Cachoeirinha, Praia do Abaís, } \\
\text { Coqueiro de Dentro, Ribuleira, Praia das Dunas, } \\
\text { Porto do Mato, Associação de Pescadores e } \\
\text { Marisqueiras do Porto do Mato, Associação das } \\
\text { Catadoras de Mangaba, Movimento das } \\
\text { Marisqueiras de Sergipe }\end{array}$ \\
\hline $\begin{array}{c}\text { Catadoras de } \\
\text { mangaba }\end{array}$ & $\begin{array}{l}\text { Catadoras } \\
\text { extrativistas } \mathrm{x} \\
\text { construtoras }\end{array}$ & Mangaba & $\begin{array}{l}\text { Manuel Dias, Cachoeirinha, Coqueiro de Dentro, } \\
\text { Ribuleira, Porto do Mato, Associação de } \\
\text { Pescadores e Marisqueiras do Porto do Mato, } \\
\text { Associação das Catadoras de Mangaba, } \\
\text { Movimento das Marisqueiras de Sergipe }\end{array}$ \\
\hline Cocoicultura & $\begin{array}{l}\text { Produtores } \mathrm{x} \\
\text { moradores } \\
\text { locais }\end{array}$ & Coco & $\begin{array}{l}\text { Manuel Dias, Cachoeirinha, Praia do Abaís, } \\
\text { Ribuleira, Porto do Mato, Coqueiro de Dentro, } \\
\text { Associação das Catadoras de Mangaba }\end{array}$ \\
\hline Água & $\begin{array}{l}\text { DESO } x \\
\text { moradores } \\
\text { locais }\end{array}$ & Água & $\begin{array}{l}\text { Manuel Dias, Cachoeirinha, Praia do Abaís, } \\
\text { Ribuleira, Praia das Dunas, Porto do Mato, } \\
\text { Associação de Pescadores e Marisqueiras do Porto } \\
\text { do Mato, Associação das Catadoras de Mangaba }\end{array}$ \\
\hline Lagos & $\begin{array}{l}\text { APA } x \text { donos } \\
\quad \text { de } \\
\text { restaurantes e } \\
\text { bares e } \\
\text { construtoras }\end{array}$ & Lagos & $\begin{array}{l}\text { Manuel Dias, Cachoeirinha, Praia do Abaís, } \\
\text { Ribuleira, Associação de Pescadores e } \\
\text { Marisqueiras do Porto do Mato, Coqueiro de } \\
\text { Dentro, Associação das Catadoras de Mangaba }\end{array}$ \\
\hline
\end{tabular}

Fonte: Elaborado pelo autor a partir de dados coletados em pesquisa de campo.

A disputa sobre a distribuição dos recursos naturais caracteriza a dimensão política. As disputas sobre o acesso aos recursos naturais, delimita a dimensão social, as quais podem ocorrer sobre recursos tidos como de domínio público ou aqueles onde existem sobreposição direta. Por fim, as disputas em torno do controle formal dos recursos, demarca a dimensão jurídica dos mesmos (LITTLE, 2001).

Com base na análise dos dados coletados identificou-se, nas comunidades integrantes da APA do litoral de Estância, as seguintes espécies de conflitos socioambientais que se enquadram nessa tipologia Littleana:

a) Carcinicultura clandestina versus carcinicultura legal: a carcinicultura em Sergipe remete aos tempos coloniais (LIMA; SILVA, 2014). Ela tem exercido forte atuação na redução dos manguezais do entorno da APA Litoral Sul que perpassa pelo litoral de Estância, principalmente nas proximidades do Rio Fundo, mais ao norte, e do Rio Piauí, mais ao sul da mesma, na desembocadura do Rio Real. Trata-se de uma atividade seletiva (SILVA, 2004), cuja prática clandestina é a 
que mais cresce e cujo aspecto poluidor dos rios da APA é preocupante (ARAÚJO, 2014), e que é retratado por inúmeros estudos, tanto na APA Litoral Sul, como em outras localidades do Estado.

b) pesca artesanal versus pesca industrial de arrasto: a pesca artesanal é outra das atividades extrativistas mais antigas desenvolvidas na área (ARAÚJO, 2014). Ela tem sofrido com a pesca industrial de arrasto, que acontece ilegalmente em alto mar, principalmente na altura da praia do Abaís. Isso tem levado muitos pescadores artesanais a abandonar sua vocação primeira para assumir outras funções nas comunidades, tendo em vista a sua sobrevivência e a de suas famílias. Além disso, as restrições impostas pelos latifundiários aos pescadores (GONÇALVES, 2015), bem como a instalação de carciniculturas no Brasil, que expropria os pescadores e extrativistas de suas comunidades, têm gerado conflitos (MUHLERT, 2014).

c) cata do caranguejo em período permitido versus catadores locais em época reprodutiva do caranguejo: a cata do caranguejo em período de andada, ou seja, em tempo de sua reprodução, tem sido uma constante, principalmente entre os moradores locais, os quais possuem um conhecimento aprofundado de seus ecossistemas, porém, pouco valorizados pelas políticas públicas (LIMA; SILVA, 2014). A legislação ambiental no tocante a essa proibição é conhecida por todos, mas observada por poucos. Eles alegam constituir alimento importante para a sua sobrevivência para cometerem tal ilícito. Esse conflito está situado nas áreas de mangues na foz dos rios Real e Piauí.

d) manguezais/APA versus construtoras/clandestinos: os manguezais constituem-se como um dos recursos naturais mais importantes da APA. Em torno dele se desenvolvem várias espécies animais e vegetais. Além disso são verdadeiros protetores naturais das margens da foz dos rios Real e Piauí que por ali desaguam no Oceano Atlântico. Eles vêm sofrendo conflitos ocasionados pelos fatores econômicos e turísticos, os quais acentuaram-se pós-construção da rodovia SE-100 (FONSECA; VILAR; SANTOS, 2008). Além disso, eles vêm sendo suprimidos pelas atividades aquicultoras, como a da carcinicultura (CARVALHO, 2010).

e) flora/APA versus construtoras/clandestinos: a vegetação de restinga e os manguezais, bem como resquícios da Mata Atlântica, perfazem parcela importante da configuração da paisagem natural desse ambiente. A perda parcial ou total da vegetação original da APA Litoral Sul de Sergipe constitui-se como um dos 
impactos resultantes do conflito de ocupação urbana de segundas residências versus implantação da APA (SANTOS; VILAR, 2013). Isso se deve ao processo de ocupação do Litoral Sul de Sergipe e do Litoral Norte da Bahia, que contribuiu para acelerar a degradação da flora (SANTOS, 2017).

f) fauna/APA versus caçadores clandestinos: a preservação das espécies animais nativas têm sofrido as ameaças dos caçadores clandestinos, os quais geralmente são moradores locais, que caçam os animais para finalidades de alimentação, uso zooterápico, mágico, artesanato, religioso, etc, e utilizam as estratégias de caça com cachorro e a caça de espera (ALMEIDA, 2018). Esses animais silvestres estão presentes em diferentes habitats espalhados ao longo da APA. A caça está entre as quatro ameaças mais importantes das UCs, além da infraestrutura, das queimadas e da pecuária (FERREIRA, 2011).

g) catadoras de mangaba versus construtoras/especulação imobiliária: trata-se de um dos conflitos mais relevantes na APA do litoral de Estância, principalmente nas comunidades Ribuleirinha e Manuel Dias. As catadoras de mangaba enfrentam uma dupla invisibilidade, caracterizada por serem tradicionais e por serem mulheres (SANTOS; SOUZA, 2016). Por outro viés, a maior demanda das catadoras é o acesso à terra, e a maior ameaça é a falta de organização social das mesmas (COSTA; SOUZA; MENDONÇA, 2018). O cercamento dessas áreas, bem como dos latifúndios e das propriedades particulares têm dificultado o acesso das catadoras às árvores e seus frutos (SILVA; SOUZA, 2011). Além disso, a exploração turística e a especulação imobiliária têm ameaçado a existência dessa cultura (MOTA, 2005).

h) cocoicultura versus moradores locais: a cultura da cocoicultura foi implantada em Sergipe na década de 1960, em substituição a da cana-de-açúcar (ALMEIDA, 2018). Por conta das condições propícias do solo, o coco-da-baía apresenta sua maior produção nos municípios da planície litorânea de Sergipe (CARVALHO, 2010). Nas proximidades do Rio Real ela acontece em planície fluviomarinha, em cultivos de caráter permanente, e consorciada com a pecuária extensiva (SANTOS, 2017). Os latifundiários e os moradores locais disputam o acesso aos recursos naturais disponíveis nessa área, e até mesmo o acesso a comunidade local, como no caso do povoado Massadiço, onde o conflito gerou até o homicídio de um morador da comunidade.

i) água versus moradores locais: embora constitua uma área rica em recursos hídricos, seja pela presença de rios, lagos, lagoas e demais corpos d'água, 
a qualidade da água disponível para o consumo é geradora de conflitos entre os moradores locais. A água oriunda de poços artesianos possui uma coloração amarelada, cuja qualidade é questionada. Isto difere da água ofertada pela DESO, a qual vem de Itaporanga d'Ajuda. O desigual acesso aos recursos hídricos por parte das populações ilustra claramente a atual situação de injustiça ambiental (PORTOGONÇALVES, 2004). É necessária a proteção dos recursos hídricos no litoral de Estância, através do monitoramento da qualidade da água dos poços tubulares que abastecem as residências locais (SANTOS; VILAR, 2013).

j) lagoas/APA versus donos de bares/restaurantes/construtoras: os lagos e as lagoas, na área denominados de lagoa dos tambaquis, na proximidade os povoados da praia do Abaís, Manuel Dias, Coqueiro de Dentro, Coqueiro de Fora, Cachoeirinha e adjacências, como quaisquer outros corpos d'água, constituem-se propriedade da União. Contrariando essa normativa, eles estão praticamente cercados pelas propriedades ao seu redor, constituídas em sua maioria por bares, restaurantes e construtoras, os quais fizeram desse recurso propriedade privada e fonte de atividades econômicas. Ademais, os mesmos são utilizados frequentemente por turistas e banhistas, e estão sujeitos a toda espécie de poluição.

\section{Conflitos Socioambientais em torno dos impactos gerados pela ação humana e natural}

A tipologia de Little (2001) que versa sobre os conflitos em torno dos impactos gerados pela ação humana e natural, conforme disposto no Quadro 2, sintetiza quase metade, $49 \%$, dos Conflitos Socioambientais encontrados na APA estanciana. Sua ocorrência estende-se por diversas comunidades ao longo da APA e caracterizam-se por sua gênese interesses econômicos, turísticos, imobiliários, privados, etc. Nesta tipologia encontramos os Conflitos Socioambientais que mais agridem o meio ambiente e que comprometem a sua sustentabilidade.

Quadro 2 - Planilha de conflitos em torno dos impactos ambientais e sociais gerados pela ação humana e natural.

\begin{tabular}{c|c|c|c}
\hline $\begin{array}{c}\text { TIPO DE } \\
\text { CONFLITO }\end{array}$ & $\begin{array}{c}\text { ATORES } \\
\text { ENVOLVIDOS }\end{array}$ & $\begin{array}{c}\text { RECURSOS } \\
\text { EM } \\
\text { DISPUTA }\end{array}$ & LOCAIS DE OCORRÊNCIA \\
\hline $\begin{array}{c}\text { Dunas na } \\
\text { Rodovia }\end{array}$ & DNIT x Prefeitura & $\begin{array}{c}\text { Acesso } \\
\text { rodoviário }\end{array}$ & $\begin{array}{c}\text { Praia das Dunas, Associação dos Pescadores } \\
\text { e Marisqueiras do Porto do Mato }\end{array}$ \\
\hline Dunas nas & APA x & Uso do solo & Praia das Dunas, Associação dos Pescadores \\
\hline
\end{tabular}




\begin{tabular}{|c|c|c|c|}
\hline $\begin{array}{c}\text { casas e } \\
\text { construções }\end{array}$ & proprietários & & $\begin{array}{l}\text { e Marisqueiras do Porto do Mato, Praia do } \\
\text { Abaís, Movimento das Marisqueiras de Sergipe }\end{array}$ \\
\hline Pecuária & APA $\times$ pecuaristas & Uso do solo & $\begin{array}{c}\text { Praia das Dunas, Associação dos Pescadores } \\
\text { e Marisqueiras do Porto do Mato, Praia do } \\
\text { Abaís, Movimento das Marisqueiras de } \\
\text { Sergipe, Coqueiro de Dentro, Porto do Mato, } \\
\text { Ribuleira, Associação das Catadoras de } \\
\text { Mangaba }\end{array}$ \\
\hline Bugues & APA $x$ bugueiros & Dunas & $\begin{array}{c}\text { Praia das Dunas, Associação dos Pescadores } \\
\text { e Marisqueiras do Porto do Mato, Praia do } \\
\text { Abaís, Movimento das Marisqueiras de } \\
\text { Sergipe, Porto do Mato, Ribuleira, } \\
\text { Cachoeirinha }\end{array}$ \\
\hline $\begin{array}{l}\text { Casas de } \\
\text { veraneio e de } \\
2^{\underline{a}} \text { residência }\end{array}$ & $\begin{array}{c}\text { APA x } \\
\text { proprietários }\end{array}$ & $\begin{array}{l}\text { Uso do solo } \\
\text { (inclusive } \\
\text { preamar) }\end{array}$ & $\begin{array}{l}\text { Praia das Dunas, Associação dos Pescadores } \\
\text { e Marisqueiras do Porto do Mato, Praia do } \\
\text { Abaís, Movimento das Marisqueiras de } \\
\text { Sergipe, Porto do Mato, Ribuleira, Associação } \\
\text { das Catadoras de Mangaba }\end{array}$ \\
\hline $\begin{array}{l}\text { Especulação } \\
\text { Imobiliária }\end{array}$ & $\begin{array}{c}\text { Especulação } \\
\text { imobiliária x } \\
\text { APA/moradores } \\
\text { locais }\end{array}$ & $\begin{array}{l}\text { Uso do solo } \\
\text { e lagos }\end{array}$ & $\begin{array}{l}\text { Praia das Dunas, Associação dos Pescadores } \\
\text { e Marisqueiras do Porto do Mato, Praia do } \\
\text { Abaís, Movimento das Marisqueiras de } \\
\text { Sergipe, Coqueiro de Dentro, Ribuleira, } \\
\text { Associação das Catadoras de Mangaba, } \\
\text { Cachoeirinha, Manuel Dias }\end{array}$ \\
\hline $\begin{array}{l}\text { Ponte Gilberto } \\
\text { Amado }\end{array}$ & $\begin{array}{l}\text { Governo federal } \mathrm{x} \\
\text { balsas }\end{array}$ & Acesso local & Porto do Mato \\
\hline $\begin{array}{l}\text { Resíduos } \\
\text { sólidos }\end{array}$ & $\begin{array}{c}\text { Prefeitura/APA x } \\
\text { moradores e } \\
\text { turistas }\end{array}$ & $\begin{array}{l}\text { Praias, solo } \\
\text { e corpos } \\
\text { d'água }\end{array}$ & $\begin{array}{l}\text { Praia das Dunas, Associação dos Pescadores } \\
\text { e Marisqueiras do Porto do Mato, Movimento } \\
\text { das Marisqueiras de Sergipe, Porto do Mato, } \\
\text { Ribuleira, Cachoeirinha, Manuel Dias }\end{array}$ \\
\hline Esgoto & $\begin{array}{l}\text { Prefeitura/APA x } \\
\text { moradores }\end{array}$ & $\begin{array}{c}\text { Praias, solo } \\
\text { e corpos } \\
\text { d'água }\end{array}$ & $\begin{array}{l}\text { Praia das Dunas, Associação dos Pescadores } \\
\text { e Marisqueiras do Porto do Mato, Movimento } \\
\text { das Marisqueiras de Sergipe, Coqueiro de } \\
\text { Dentro, Cachoeirinha, Manuel Dias }\end{array}$ \\
\hline $\begin{array}{l}\text { Construções } \\
\text { ilegais }\end{array}$ & $\begin{array}{l}\text { Prefeitura/APA x } \\
\text { invasores }\end{array}$ & Uso do solo & $\begin{array}{l}\text { Praia das Dunas, Associação dos Pescadores } \\
\text { e Marisqueiras do Porto do Mato, Praia do } \\
\text { Abaís, Movimento das Marisqueiras de } \\
\text { Sergipe, Porto do Mato, Ribuleira, Associação } \\
\text { das Catadoras de Mangaba, Manuel Dias }\end{array}$ \\
\hline Segurança & $\begin{array}{l}\text { Prefeitura/PM x } \\
\text { criminosos }\end{array}$ & Bens móveis & $\begin{array}{l}\text { Praia das Dunas, Associação dos Pescadores } \\
\text { e Marisqueiras do Porto do Mato, Coqueiro de }\end{array}$ \\
\hline
\end{tabular}




\begin{tabular}{|c|c|c|c|}
\hline & & & $\begin{array}{c}\text { Dentro, Porto do Mato, Ribuleira, Associação } \\
\text { das Catadoras de Mangaba, Cachoeirinha, } \\
\text { Manuel Dias }\end{array}$ \\
\hline Drogas ilícitas & $\begin{array}{l}\text { Prefeitura/PM x } \\
\text { comunidade local }\end{array}$ & Saúde & $\begin{array}{l}\text { Praia das Dunas, Associação dos Pescadores } \\
\text { e Marisqueiras do Porto do Mato, Praia do } \\
\text { Abaís, Movimento das Marisqueiras de } \\
\text { Sergipe, Coqueiro de Dentro, Porto do Mato, } \\
\text { Associação das Catadoras de Mangaba, } \\
\text { Cachoeirinha, Manuel Dias }\end{array}$ \\
\hline Projeto Tamar & $\begin{array}{l}\text { APA x moradores } \\
\text { locais/turistas }\end{array}$ & $\begin{array}{c}\text { Tartarugas } \\
\text { marinhas } \\
\text { Oliva }\end{array}$ & Praia do Abaís \\
\hline $\begin{array}{l}\text { Poluição } \\
\text { sonora }\end{array}$ & $\begin{array}{c}\text { Turistas/banhistas } \\
\text { x moradores } \\
\text { locais }\end{array}$ & $\begin{array}{l}\text { Paz e ordem } \\
\text { sociais }\end{array}$ & $\begin{array}{l}\text { Praia do Abaís, Praia das Dunas, Praia do } \\
\text { Saco, Cachoeirinha }\end{array}$ \\
\hline $\begin{array}{l}\text { Derramamento } \\
\text { de óleo na } \\
\text { praia }\end{array}$ & $\begin{array}{l}\text { APA x poluidor } \\
\text { desconhecido }\end{array}$ & $\begin{array}{l}\text { Praias, } \\
\text { fauna e flora }\end{array}$ & $\begin{array}{l}\text { Praia do Abaís, Praia da Boa Viagem, Praia } \\
\text { das Dunas, Praia do Saco }\end{array}$ \\
\hline
\end{tabular}

Fonte: Elaborado pelo autor a partir de dados coletados em pesquisa de campo.

Nessa classificação foram diagnosticados os casos de contaminação do meio ambiente, que geram Conflitos Socioambientais de diferentes proporções nas comunidades. Outro aspecto é o do esgotamento de recursos naturais, o qual origina conflitos diferenciados, pois ocasiona uma repercussão no futuro que é difícil de se quantificar. Ademais, a degradação dos ecossistemas é atrelada aos processos particulares de contaminação e esgotamento (LITTLE, 2001).

Tendo sido feita a análise dos dados coletados, reconheceu-se as seguintes espécies de Conflitos Socioambientais que se enquadram nessa tipologia Littleana:

a) dunas na rodovia versus DER/SE e Prefeitura: as dunas móveis localizadas no acesso à praia do Saco foram parcialmente retiradas para a construção da SE-100. Atualmente elas moveram-se a ponto de ocupar metade da rodovia. Situação semelhante tem ocorrido na estrada de acesso à praia das Dunas, a qual está parcialmente tomada pelas dunas. Além disso, os processos de uso e ocupação do solo na Praia do Saco, em Estância, levou ao desmonte das dunas móveis para diferentes fins, principalmente para atender os interesses do turismo (VIEIRA et al., 2013).

b) dunas nas casas e construções versus APA: ao longo de sua extensão e entre as dunas móveis das praias das Dunas, do Saco, da Boa Viagem e do Abaís 
foram construídas centenas de casas de veraneio e de segunda residência. Essas construções estão em desalinho com a Resolução do CONAMA n 303/2002, a qual constitui como Área de Preservação Permanente a área localizada a trezentos metros a partir da linha de preamar. Devido à falta de planejamento seus proprietários têm sofrido prejuízos ocasionados pela erosão marítima, destruindo os imóveis, e pela movimentação das dunas, recobrindo-os de areia (SILVA; SOUZA, 2011). De acordo com Santos (2011, p. 119), "nas praias do Abaís e do Saco, o desenvolvimento associado à construção de núcleos urbanos são evidências dos danos ambientais nesta área".

c) pecuária versus APA: a pecuária extensiva é uma das atividades econômicas que remontam ao período de ocupação da APA, pois foi a primeira cultura introduzida pelos colonizadores de Sergipe (VILAR; VIEIRA, 2014). Ela impulsionou a colonização de Sergipe (CARVALHO, 2010). Encontra-se atualmente espalhada pela maioria comunidades da APA, inclusive nos povoados praianos. De tal maneira essa atividade se destaca na APA que construíram um parque de vaquejada no Povoado Ribuleira, nas proximidades da sede das catadoras de mangabas.

d) buggys versus APA: a atividade turística está intrinsecamente relacionada ao trânsito dos buggys na APA, principalmente nos povoados das praias do Saco, das Dunas, do Abaís e circunvizinhanças. No município de Estância existe uma grande quantidade de dunas e ecossistemas preservados que estão sendo ameaçados pelo crescente trânsito de buggys, entre outras atividades (SANTOS, 2012). A justiça embargou a circulação dos mesmos devido a proteção das tartarugas do Projeto Tamar. Recentemente eles conseguiram a liberação de suas atividades, pois traçaram uma rota alternativa, que evita o contato direto com a areia das praias. Porém, não é raro encontrarmos buggys transitando nas mesmas.

e) casas de veraneio e de $2^{\mathbf{a}}$ residência/área consolidada versus APA: trata-se de um dos conflitos mais sérios da APA, nas terras da União, na área de preamar das praias do Saco, das Dunas da Boa Viagem e do Abaís. A casa de veraneio ou de segunda residência é uma prática consolidada há anos na APA Litoral Sul de Sergipe e está ligada à prática do turismo (SANTOS; VILAR, 2013). Os conflitos causados pelas construções desordenadas e irregulares de residências, bares e restaurantes são comumente encontrados na orla da praia do Saco (VIEIRA; VILAR, 2014). Os moradores locais têm buscado apoio junto aos deputados estaduais para obterem o reconhecimento das áreas já construídas como áreas 
consolidadas, o que seria uma tentativa de solução para o imbróglio judicial existente.

f) especulação imobiliária versus APA/moradores locais: é comum encontrar a poluição visual de outdoors, placas de venda e anúncios, ao longo dos diversos povoados às margens da Rodovia SE-100, bem como nas áreas das praias do Saco, das Dunas e do Abaís, com informações de venda de lotes e terrenos para construção de casas. A especulação imobiliária no litoral de Estância aumenta em um ritmo frenético, levando a valoração e valorização das áreas próximas ao mar e às margens da rodovia SE-100 para construção de condomínios fechados, dificultando o acesso às mangabeiras (SANTOS, 2015). Isso gera um desafio de coexistência entre os moradores permanentes e o imobiliário-turístico (SANTOS; VILAR, 2016).

g) Ponte Gilberto Amado versus balsas: antes da inauguração da Ponte Gilberto Amado, o único meio de transporte que ligava o Porto dos Cavalos, em Estância, à Terra Caída, em Indiaroba, era fluvial, e feito por balsas. Com a construção e inauguração da mesma, esse meio fluvial de transporte foi praticamente extinto naquela localidade, prejudicando as atividades dos proprietários de balsas e de vendedores ambulantes (SANTOS, 2017). De acordo com Santos; Vilar (2016), as dinâmicas socioespaciais do litoral de Sergipe vivenciam o tempo da fluidez e da abertura territorial, superando os "hiatos geográficos" (VILAR; ARAÚJO, 2010) mediante a sua interligação por pontes.

h) resíduos sólidos versus APA: não obstante o veículo coletor de lixo passar em dias fixos pelas comunidades das margens da Rodovia SE-100, bem como nas comunidades praianas, os resíduos sólidos constituem-se como uma séria ameaça a preservação da APA do litoral de Estância. Os moradores locais ateiam fogo nos resíduos sólidos que depositam nos seus quintais. É comum também encontrar-se coletores e lixo depositado fora dos mesmos. Constatou-se o aumento da geração de lixo na APA, o qual geralmente é acondicionado em locais inadequados, além do despejo de dejetos sanitários in natura nos rios, lagoas e oceanos (SANTOS, 2017).

i) esgoto versus APA: outra grave ameaça a preservação da APA é o despejo do esgotamento das casas diretamente no solo. Isso deve-se a ausência de tratamento de esgoto na área. Com o surgimento dos condomínios fechados e a perspectiva de aumento progressivo de moradores, isso tem se tornado cada vez 
mais conflitante e, desse modo, preocupante. O esgoto despejado na APA contamina o solo e os corpos hídricos (SANTOS; VILAR, 2013).

j) construções ilegais/irregulares versus APA: as construções ilegais (ou irregulares) são uma constante ao longo de toda extensão da APA. Elas são encontradas geralmente nos povoados praianos, como nas Praias do Abaís, das Dunas e do Saco. Na APA a ocupação urbana sugere articulação ineficiente entre Estado e Município no ordenamento territorial (BRAGHINI, 2016).

k) segurança versus Prefeitura/PM: a violência e a criminalidade estão presentes em várias comunidades da APA, principalmente nas que estão às margens da Rodovia SE-100. São inúmeros os relatos de assaltos e até mesmo de homicídios por parte dos moradores locais, os quais expressam a sensação de insegurança e a inexpressiva atuação da Polícia Militar nessas comunidades. Inclusive aconteceram situações em que os moradores tiveram que enfrentar criminosos para coibir crimes cometidos pelos mesmos.

I) drogas ilícitas versus Prefeitura/PM: as drogas ilícitas são um dos conflitos mais desafiadores para a atuação dos poderes públicos e da Secretaria de Segurança Pública, nos diferentes entes federativos. Trata-se de uma realidade presente na maioria das comunidades da APA, e que ataca principalmente a juventude.

m) projeto Tamar versus moradores locais/turistas: o Projeto Tamar desenvolve importante trabalho nas praias estancianas, no tocante a preservação e da reprodução das tartarugas olivas. O litoral sergipano é o único berço de reprodução das mesmas em todo o Brasil. Há alguns anos o ICMBIO ajuizou ação denunciando o trânsito constante de carros e motos ao longo das praias, que ameaçava a sobrevivência das mesmas. Isso intensificava-se no período de veraneio, com o aumento do número de turistas.

n) poluição sonora versus moradores locais: a poluição sonora é um conflito que se intensifica no período de veraneio, quando há uma maior presença de turistas. São conflitos pontuais que acontecem, sobremaneira, nos povoados praianos e em torno da lagoa dos tambaquis. Geralmente são resolvidos pacificamente, embora, em situações mais críticas a polícia precise ser acionada para intervir e apaziguar a situação conflitante, o que enseja o recolhimento dos aparelhos de sons e paredões.

o) derramamento de óleo na praia versus APA: esse conflito é um dos mais recentes e mais impactantes para as praias do nordeste brasileiro, em 
especial, para as praias da APA do litoral de Estância. Trata-se de um dos maiores desastres ambientais do litoral do país. Até o momento não se sabe ao certo a causa do derramamento do óleo. No litoral estanciano, bem como nas áreas adjacentes e que integram a APA Litoral Sul, foram encontradas manchas de óleo nas praias do Abaís, das Dunas, do Saco, bem como nos manguezais da foz dos rios Real e Piauí, nas imediações de Terra Caída, em Indiaroba.

\section{Conflitos Socioambientais em torno do uso dos conhecimentos ambientais}

Nessa tipologia de Little (2001), salienta-se os conflitos em torno do uso dos conhecimentos ambientais, conforme apresentado no Quadro 3, os quais sintetizam $19 \%$ dos Conflitos Socioambientais encontrados na APA de Estância. Eles estão concentrados nas comunidades praianas do Abaís e do Saco, e no Porto do Mato. Caracterizam-se pelo acesso a direitos fundamentais das pessoas, bem como pelo uso dos conhecimentos ambientais, tendo em vista o desenvolvimento de atividades turísticas, religiosas, reivindicatórias, etc.

Quadro 3 - Planilha de conflitos em torno do uso dos conhecimentos ambientais.

\begin{tabular}{|c|c|c|c|}
\hline $\begin{array}{l}\text { TIPO DE } \\
\text { CONFLITO }\end{array}$ & ATORES ENVOLVIDOS & $\begin{array}{l}\text { RECURSOS EM } \\
\text { DISPUTA }\end{array}$ & LOCAIS DE OCORRÊNCIA \\
\hline $\begin{array}{c}\text { Turismo } \\
\text { local }\end{array}$ & $\begin{array}{c}\text { APA x agências de } \\
\text { turismo/moradores locais }\end{array}$ & $\begin{array}{l}\text { Praias, dunas e } \\
\text { lagos }\end{array}$ & $\begin{array}{c}\text { Praia do Abaís, Praia das Dunas, } \\
\text { Porto do Mato, Manuel Dias }\end{array}$ \\
\hline $\begin{array}{l}\text { Turismo } \\
\text { fluvial }\end{array}$ & $\begin{array}{c}\text { Marinha x } \\
\text { clandestinos/proprietários } \\
\text { de embarcações }\end{array}$ & Trânsito fluvial & $\begin{array}{c}\text { Associação dos Pescadores e das } \\
\text { Marisqueiras do Porto do Mato, Porto } \\
\text { do Mato }\end{array}$ \\
\hline Educação & $\begin{array}{l}\text { Estado/ Prefeitura x } \\
\text { comunidade local }\end{array}$ & Escolas & $\begin{array}{c}\text { Praia do Abaís, Associação dos } \\
\text { Pescadores e das Marisqueiras do } \\
\text { Porto do Mato, Coqueiro de Dentro, } \\
\text { Porto do Mato, Ribuleira, Associação } \\
\text { das Catadoras de Mangaba, } \\
\text { Cachoeirinha, Manuel Dias }\end{array}$ \\
\hline Saúde & $\begin{array}{l}\text { Prefeitura } x \text { comunidade } \\
\text { local }\end{array}$ & Posto de Saúde & $\begin{array}{c}\text { Praia do Abaís, Associação dos } \\
\text { Pescadores e das Marisqueiras do } \\
\text { Porto do Mato, Coqueiro de Dentro, } \\
\text { Porto do Mato, Ribuleira, Associação } \\
\text { das Catadoras de Mangaba, } \\
\text { Cachoeirinha, Manuel Dias }\end{array}$ \\
\hline $\begin{array}{c}\text { Capela N. } \\
\text { Sra. Boa } \\
\text { Viagem }\end{array}$ & Igreja Católica x Judiciário & Templo religioso & Praia do Saco \\
\hline
\end{tabular}




\begin{tabular}{c|c|c|c}
\hline $\begin{array}{c}\text { Acesso } \\
\text { local }\end{array}$ & $\begin{array}{c}\text { Latifundiários } \mathrm{x} \\
\text { Moradores locais }\end{array}$ & $\begin{array}{c}\text { Acesso ao porto } \\
\text { e comunidade }\end{array}$ & $\begin{array}{c}\text { Praia do Abaís, Associação dos } \\
\text { Pescadores e das Marisqueiras do } \\
\text { Porto do Mato }\end{array}$ \\
\hline
\end{tabular}

Fonte: Elaborado pelo autor a partir de dados coletados em pesquisa de campo.

Para essa classificação faz-se imprescindível as percepções de riscos dos Conflitos Socioambientais. Essa antecipação em relação aos mesmos é fundamental para evitar situações danosas ao meio ambiente. Outro aspecto relevante nessa categorização é o uso exclusivo da informação enquanto propriedade intelectual de um indivíduo ou de determinada coletividade. Por fim, os lugares tidos como sagrados também podem ocasionar conflitos da ordem das diferentes visões de mundo (LITTLE, 2001).

Através da análise dos dados coletados distinguiu-se as seguintes espécies de conflitos socioambientais que se enquadram nessa tipologia:

a) turismo local versus APA: o turismo é um elemento polarizador de conflitos socioambientais na APA de Estância, pois há maior fluxo de turistas e consequentemente do uso dos recursos naturais da mesma. Essa atividade é importante para a geração de trabalho e renda para os moradores locais. No período de veraneio aumenta-se consideravelmente a presença de turistas nas praias, movimentando pousadas, restaurantes e bares. É quando os moradores locais se dedicam a essas atividades em detrimento das do extrativismo.

b) turismo fluvial versus Marinha: o turismo fluvial e marítimo também pode ser encontrado no Porto do Mato, no porto do Cavalo, na ponta do Saco, na Praia do Saco, em Terra Caída, entre outros locais da APA no litoral de Estância. Geralmente lanchas, escunas, jet skis, tó-tó-tós e outras embarcações fazem a travessia, partindo principalmente de Terra Caída e do Porto de Cavalos, para Mangue Seco e para a llha da Sogra, em Jandaíra/BA.

c) acesso à educação versus comunidade local: as escolas estão concentradas nos Povoados do Porto do Mato, nas instalações do Centro Esperança e Vida, da Diocese de Estância, e da Praia do Abaís. O transporte, a merenda e os livros didáticos são ofertados nas mesmas. O conflito existe entre as comunidades de difícil acesso às escolas, e nos locais por onde o transporte escolar não transita, pois têm-se a demanda, mas falta as condições para correspondê-la.

d) acesso à saúde versus comunidade local: o único posto de saúde para as comunidades do litoral fica localizado no Povoado Porto do Mato, e o atendimento se dá em dias e horários específicos. Por conseguinte, as pessoas 
acabam recorrendo aos hospitais públicos das sedes dos municípios de Indiaroba e de Estância. Assim sendo, o conflito ocorre dado à precariedade da oferta do acesso à saúde pública às comunidades litorâneas. Existe, pois, a demanda, mas a oferta é insuficiente.

e) capela de N. Sra. da Boa Viagem versus Judiciário: a capela de N. Sra. da Boa Viagem, ilustrada na Figura 4, está localizada na praia do Saco, e pertence a Diocese de Estância. Constitui-se como valioso patrimônio de história, de cultura e de fé para o Estado de Sergipe, especialmente para o município de Estância, pois foi aí que os jesuítas ingressaram junto com os colonizadores em terras sergipanas. Dada a progressão das águas oceânicas ocorrida nos últimos anos nessa região, a mesma ficou ameaçada de ser destruída, ensejando a intervenção judicial, gerando o conflito.

Figura 4 - Molhe para proteção da capela de N. Sra. da Boa Viagem na Praia do Saco.

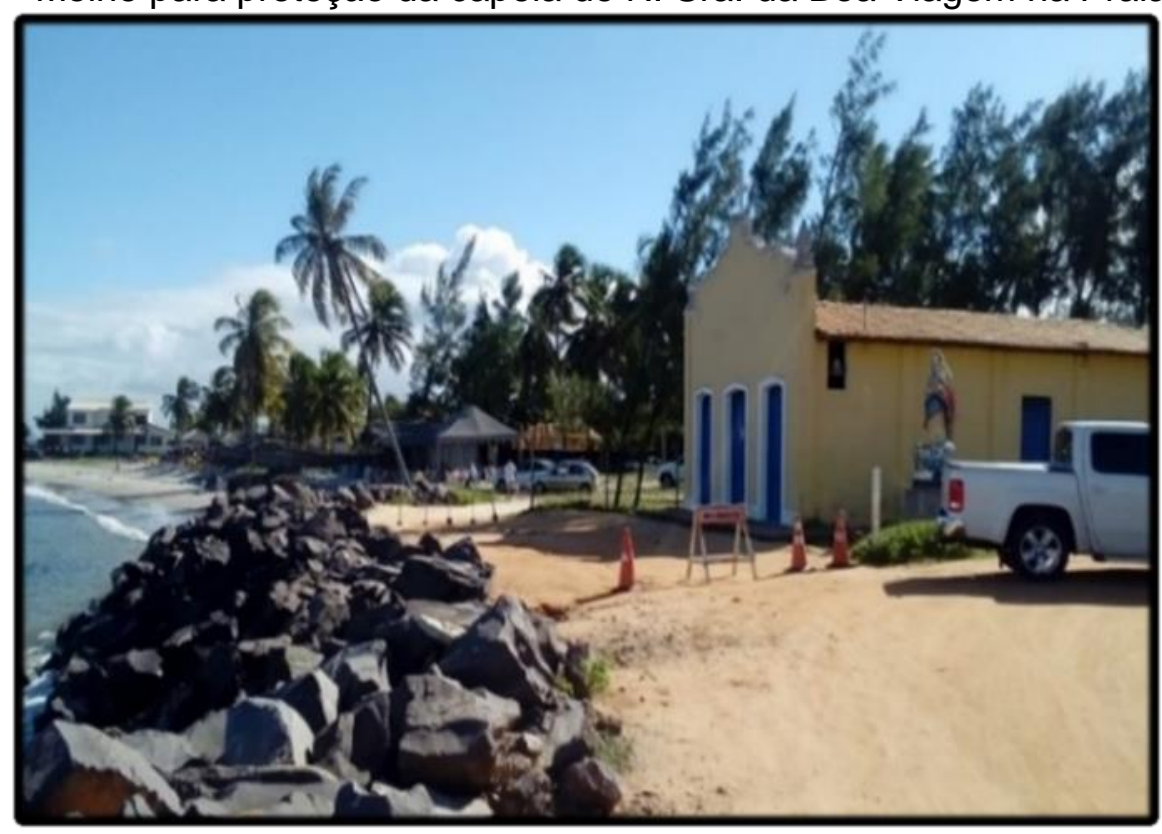

Fonte: Fagner Santos de Oliveira, 2019.

f) acesso local versus latifundiários: esse tipo de conflito acontece principalmente no Povoado Massadiço, onde o proprietário da Fazenda Estiva está no polo oposto da questão, pois sua propriedade integra a área que dá acesso ao porto da comunidade. Esse conflito acabou culminando na morte de um morador local, o qual desobedeceu às ordens de não ingressar na área da fazenda. 


\section{Considerações Finais}

A APA do litoral de Estância é uma Unidade de Conservação caracterizada pela presença de diversos recursos naturais. Por isso, como qualquer outro ambiente litorâneo, está bastante vulnerável às ações humanas e, por conseguinte, aos Conflitos Socioambientais. Estes decorrem da imposição de interesses dominantes sobre as interações ecológicas e sociais. No convívio social e nas interações da sociedade com o meio ambiente travam-se embates entre os mais distintos interesses e vontades. Uns subjugam-se a outros. O viés econômico, por vezes, exerce influência preponderante sobre os mesmos.

Por isso, o objetivo da criação do Sistema Nacional de Unidades de Conservação (SNUC) é possibilitar a conservação dos ambientes naturais e disciplinar o uso sustentável dos recursos disponíveis na natureza. A legislação ambiental nasce justamente para garantir que os conflitos socioambientais possam ser resolvidos de forma pacífica, respeitando o direito líquido e certo de cada cidadão, sem descuidar da preservação do bem natural.

As questões atreladas a preservação dos recursos naturais na APA em estudo, ainda carecem de um instrumento primordial, para o direcionamento das ações humanas nesse ambiente. Embora o PEGC (Plano e o Sistema Estadual de Gerenciamento Costeiro) constitui-se como um valioso instrumental jurídico de preservação da APA, o Plano de Manejo se impõe como uma necessidade. Ambos ainda não existem enquanto legislação promulgada e, portanto, não são aplicadas na práxis dessas comunidades.

A análise do mapa dos conflitos socioambientais possibilitou perceber que os mesmos estão espacializados em toda a extensão da APA do litoral de Estância/SE. Sua distribuição concentra-se nas praias do Abaís, das Dunas e do Saco, bem como no entorno da lagoa dos tambaquis, na altura do povoado Cachoeirinha, e ao longo da extensão da rodovia SE-100, principalmente na altura dos povoados Manuel Dias, Ribuleirinha e Porto do Mato. Tratam-se de comunidades muito povoadas e constantemente visitadas por turistas.

Constatou-se que os moradores locais, em sua maioria, desconhecem a natureza e finalidades jurídicas da APA em destaque. Com algumas exceções, sobremodo, dos responsáveis pelos órgãos do poder público responsáveis pela mesma, a exemplo da SEMA, da ADEMA, da APA Litoral Sul, entre outros, os quais conhecem satisfatoriamente acerca dessas unidades ambientais. Ademais, as 
atuações fiscalizatórias que ocorrem na APA em evidência, as quais ocorrem com maior frequência no período de veraneio e são direcionadas principalmente aos moradores locais, cuja predominância se dá aos moldes de caráter punitivo em detrimento do preventivo.

Contudo, constatou-se, pela análise final dos dados, o aumento nos conflitos socioambientais nessa área decorrentes: do desconhecimento da natureza e das atribuições de uma APA; dos interesses em usufruir dos bens materiais, através da instituição das segundas residências; do turismo sem base sustentável; da falta de ação do poder público no tocante a fiscalização e implementação da legislação vigente; etc. Todas essas situações geram uma tensão constante no equilíbrio e na conservação da biodiversidade da mesma. Por fim, o questionamento das práticas atuais, nos permite avaliar o conhecimento e a aplicabilidade de outras práticas, que possam promover o uso sustentável da APA estanciana.

\section{REFERÊNCIAS}

ALMEIDA, M. C. S. Conhecimento e usos da mastofauna cinegética por caçadores, em Unidades de Conservação Particulares no município de Santa Luzia do Itanhy, Sergipe. 2018. Monografia (Bacharelado em Ecologia) - Universidade Federal de Sergipe, São Cristóvão/SE, 2018.

ARAÚJO, L. R. R. de. Conflitos territoriais no processo de implantação da reserva extrativista (RESEX) do Litoral Sul de Sergipe. 2014. Dissertação (Mestrado em Ecologia) - Universidade Federal de Sergipe, São Cristóvão/SE, 2014.

BRAGHINI, C. R. Gestão territorial de Unidades de Conservação no litoral sergipano. 2016. Tese (Doutorado em Ecologia) - Universidade Federal de Sergipe, São Cristóvão/SE, 2016.

BRASIL. Lei no 9.985, de 18 de julho de 2000. Institui o Sistema Nacional de Unidades de Conservação da Natureza e dá outras providências. Diário Oficial da União, Brasília, DF, 18 jul. 2000. Disponível em: http://www.planalto.gov.br/ccivil 03/LEIS/L9985.htm. Acesso em: 20 mar. 2020.

BRASIL. Resolução CONAMA nํ 303, de 20 de março de 2002. Dispõe sobre os parâmetros, definições e limites de Áreas de Preservação Permanente de reservatórios artificiais e o regime de uso do entorno. Diário Oficial da União: Seção 1, Brasília, DF, p. 67-68, 13 mai. 2002.

BURSZTYN, M. (Org.). A difícil sustentabilidade: política energética e conflitos ambientais. Rio de Janeiro: Garamond, 2001.

CARVALHO, M. E. S. A carcinicultura na Zona Costeira do Estado de Sergipe. 2004.

Dissertação (Mestrado em Geografia) - Universidade Federal de Sergipe, São Cristóvão/SE, 2004. 
CARVALHO, M. E. S. A questão hídrica na bacia sergipana do rio Vaza Barris. 2010. Tese (Doutorado em Geografia) - Universidade Federal de Sergipe, São Cristóvão/SE, 2010.

COSTA, J. de J.; SOUZA, R. M. e.; MENDONÇA, F. de A. Distribution and Exploitation of Mangaba (Hancornia speciosa Gomes) in Sergipe, Northeast, Brazil. Revista Brasileira de Geografia Física, v. 11, n. 18, 2018.

DRUMMOND, J. A. Conceitos básicos para a análise de situações de conflito em torno de recursos naturais. In: BURSZTYN, M. (Org.). A difícil sustentabilidade: política energética e conflitos ambientais. Rio de Janeiro: Garamond, 2001. p. 65-77.

FERREIRA, M. N. Planejamento sistemático das Unidades de Conservação no Estado do Tocantins. 2011. Tese (Doutorado em Ecologia) - Universidade de São Paulo, São Paulo/SP, 2011.

FONSECA, V.; VILAR, J. W. C.; SANTOS, M. A. N. Reestruturação territorial do litoral de Sergipe. In: VILAR, J. W. C.; ARAÚJO, H. M. Território, meio ambiente e turismo no litoral sergipano. São Cristóvão: Edufs, 2010. p. 40-61.

GONÇALVES, F. D. S. O processo de criação da reserva extrativista marinha do litoral sul de Sergipe: embates e limites. 2015. Dissertação (Mestrado em Desenvolvimento e Meio Ambiente) - Universidade Federal de Sergipe, São Cristóvão/SE, 2015.

HOUAISS, A. Dicionário Houaiss da Língua Portuguesa. Rio de Janeiro: Objetiva, 2001.

LIMA, J. S. G.; SILVA, C. A. da. Carcinicultura marinha familiar no estuário do Rio VazaBarris, Sergipe: implicações para uma produção sustentável. Brasília/DF: Embrapa, 2014.

MOTA, D. M. da. A mangabeira as Catadoras o Extrativismo. Belém/PA: EMBRAPA, 2005.

MUHLERT, A. C. S. Indicadores de sustentabilidade da carcinicultura em terras baixas, São Cristóvão, Sergipe. 2014. Dissertação (Mestrado em Desenvolvimento e Meio Ambiente) - Universidade Federal de Sergipe, São Cristóvão/SE, 2014.

NASCIMENTO, D. T. O papel dos conflitos socioambientais e de fenômenos climáticos extremos no fortalecimento da gestão ambiental municipal no Sul Catarinense. 2015. Tese (Doutorado em Geografia) - Universidade de Brasília, Brasília/DF, 2015.

OLIVEIRA, A. C. C. de A. Análise do estado ambiental da planície costeira de EstânciaSergipe como subsídio de ordenamento territorial. Estudios Teritoriales, São Paulo, p. 3240-3264, set. 2014.

PORTO-GONÇALVES, C. W. O Desafio Ambiental. Rio de Janeiro: Record, 2004. SANTOS, C. N. C. dos. Entre o litoral sul de Sergipe e o litoral norte da Bahia: onde as políticas territoriais se encontram. 2017. Tese (Doutorado em Geografia) - Universidade Federal de Sergipe, São Cristóvão/SE, 2017.

SANTOS, C. N. C. dos; VILAR, J. W. C. Territórios e conflitos ambientais do turismo de segunda residência na APA Litoral Sul (SE). Revista Ateliê Geográfico, v. 7, n. 2, 2013.

SANTOS, C. N. C. dos; VILAR, J. W. C. Os conflitos ambientais da implantação do imobiliário-turístico no litoral de Sergipe. Revista Geosaberes, Fortaleza, v. 6, n. 3, jul. 2016. 
SANTOS, E. A.; SOUZA, R. M. e. Territorialidade das catadoras de mangaba no litoral sul de Sergipe. In: Geosaberes, Fortaleza, v. 6, n. 3, p. 629-642, jul. 2016.

SANTOS, M. A. dos. Análise geoambiental do município costeiro de Estância Sergipe. 2011. Dissertação (Mestrado em Geografia) - Universidade Federal de Sergipe, São Cristóvão/SE, 2011.

SANTOS, P. P. Entre a casa de praia e o imobiliário-turístico: a segunda residência no litoral sergipano. 2015. Dissertação (Mestrado em Geografia) - Universidade Federal de Sergipe, São Cristóvão/SE, 2015.

SANTOS, S. S. C. dos. Conservação versus conflitos socioambientais (Comunidade Jatobá) no futuro Parque Estadual das Dunas: Barra dos Coqueiros, Sergipe. 2012. Dissertação (Mestrado em Desenvolvimento e Meio Ambiente) - Universidade Federal de Sergipe, São Cristóvão/SE, 2012.

SERGIPE. Decreto $n^{\circ} 13.468$, de 21 de janeiro de 1993. Institui a Área de Proteção Ambiental do Litoral Sul do Estado de Sergipe. Diário Oficial do Estado, Aracaju, SE, 27 jan. 1993. Disponível em: https://semarh.se.gov.br/wpcontent/uploads/2017/01/decreto_n.\%C2\%BA_13.468.pdf. Acesso em: 20 mar. 2020.

SERGIPE. Projeto de Lei $n^{\circ} 263$, de 07 de novembro de 2019. Institui o Plano e o Sistema Estadual de Gerenciamento Costeiro - PEGC. Diário Oficial do Estado, Aracaju, SE, 2019.

SILVA, M. do S. F. da.; SOUZA, R. M. e. Território usado e implicações do turismo na APA Litoral Sul em Sergipe. Revista Nordestina de Ecoturismo, Aquidabã/SE, v. 4, n. 2, 2011.

VIEIRA, L. V. L. et al. Praia do Saco em Estância/SE: análise dos processos de uso e ocupação do solo costeiro. Rev. Eletrônica da Faculdade José Augusto Vieira, Lagarto/SE, ano VI, 2013.

VIEIRA, L. V. L.; VILAR, J. W. C. Conflitos ambientais em Sergipe. Aracaju: IFS, 2014. VILAR, J. W. C.; ARAÚJO, H. M. de. Iniciativas de ordenamento territorial no litoral sul de Sergipe. In: VILAR, J. W. C.; ARAÚJO, H. M. Território, meio ambiente e turismo no litoral sergipano. São Cristóvão: Editora UFS, 2010.

\section{NOTAS DE AUTOR}

\section{CONTRIBUIÇÃO DE AUTORIA}

Fagner Santos de Oliveira - Concepção. Coleta de dados, Análise de dados, Elaboração do manuscrito, revisão e aprovação da versão final do trabalho

Márcia Eliane Silva Carvalho - Concepção e elaboração do manuscrito. Coleta de dados Participação ativa da discussão dos resultados; Revisão e aprovação da versão final do trabalho.

\section{FINANCIAMENTO}

Não se aplica.

CONSENTIMENTO DE USO DE IMAGEM

Não se aplica.

APROVAÇÃO DE COMITÊ DE ÉTICA EM PESQUISA

Não se aplica. 


\section{LICENCCA DE USO}

Este artigo está licenciado sob a Licença Creative Commons CC-BY. Com essa licença você pode compartilhar, adaptar, criar para qualquer fim, desde que atribua a autoria da obra.

\section{HISTÓRICO}

Recebido em: 15-04-2020

Aprovado em: 26-08-2021 